\title{
Micropropagação fotoautotrófica e uso da luz natural
}

\author{
Photoautotrophic micropropagation and use of the natural light
}

\author{
Alan Cristiano Erig ${ }^{1}$ Márcia Wulff Schuch ${ }^{2}$
}

- REVISÃO BIBLIOGRÁFICA -

\section{RESUMO}

Apesar da micropropagação ser amplamente difundida e apresentar vantagens em relação aos métodos tradicionais de propagação, seu emprego em escala comercial na produção de mudas é limitado, principalmente, devido ao elevado custo para obtenção das mudas. $O$ desenvolvimento de sistemas de micropropagação fotoautotrófica com o uso de luz natural surgem como possibilidades potenciais de aumentar a eficiência da micropropagação e auxiliar na redução dos custos, viabilizando-a comercialmente. No entanto, a micropropagação fotoautotrófica e o uso da luz natural carecem de estudos. No Brasil, pesquisas com o intuito de utilização da luz natural na micropropagação fotoautotrófica são praticamente inexistentes, apesar de haverem fortes razões para sua pesquisa e implementação, principalmente, pelo fato de o Brasil ser um país de clima tropical e subtropical, com grande disponibilidade de luz natural ao longo do ano, e por necessitar de novas tecnologias para o setor de produção de mudas. Esta revisão visa discutir aspectos relacionados à micropropagação fotoautotrófica e utilização da luz natural, como possibilidades para auxiliar a tornar a micropropagação um método de produção de mudas comercialmente viável.

Palavras-chave: cultura de tecidos, fotossíntese, sacarose, autotrófica, luz solar, redução de custo.

\section{ABSTRACT}

In spite of the micropropagation to be diffused thoroughly and to present advantages in relation to the traditional methods of propagation, its use in commercial scale in the scions production is limited, mainly, due to the high cost for scions obtaintion. The development of photoautotrophic micropropagation systems with the use of natural light appears as potential possibilities of increasing the efficiency of the micropropagation and help in the cost reduction, making it possible commercially. However, the photoautotrophic micropropagation and the use of natural light lack studies. In Brazil, researches with the intention of the use of the natural light in the photoautotrophic micropropagation are practically inexistent, in spite of there bring strong reasons for its research and implementation, mainly, for the fact of Brazil being a country of tropical and subtropical climate, with great readiness of natural light along the year, and being in need of new technologies for the scions production section. This review seeks to discuss aspects related to the photoautotrophic micropropagation and the use of natural light, as possibilities making turn the micropropagation a method of scions production viable commercially.

Key words: tissue culture, photosynthesis, sucrose, autotrophic, sunlight, cost reduction.

\section{INTRODUÇÃO}

A micropropagação é um método de propagação vegetativa amplamente estudado nas mais diversas espécies vegetais, sendo a modalidade dentro

'Programa de Pós-graduação em Agronomia (PPGA), área de concentração em Fruticultura de Clima Temperado, Faculdade de Agronomia Eliseu Maciel (FAEM), Universidade Federal de Pelotas (UFPel). CP 354, 96.010-900, Pelotas, RS, Brasil. E-mail: acerig@ufpel.tche.br Bolsista Coordenação de Aperfeiçoamento de Pessoal de Nível Superior (CAPES). Autor para correspondência.

${ }^{2}$ Departamento de Fitotecnia, Faculdade de Agronomia Eliseu Maciel (FAEM), Universidade Federal de Pelotas (UFPel), CP 354, 96010-900, Pelotas, RS, Brasil. E-mail: marciaws@ufpel.tche.br. 
da cultura de tecidos, que mais tem difundido e encontrado aplicações práticas comprovadas. Entre as vantagens de sua utilização, estão a possibilidade de obterem-se várias plantas a partir de um explante inicial, independentemente da estação do ano; a redução do tempo e da área necessária à propagação da espécie; as melhores condições sanitárias por meio do cultivo de meristemas previamente tratados por termoterapia, para eliminação de doenças; a reprodução do genótipo da planta-mãe, geralmente, com fidelidade durante a multiplicação e; a propagação vegetativa de espécies difíceis de serem propagadas por outros métodos. Entretanto, o emprego da micropropagação em escala comercial na produção de mudas pode ser limitado, devido, entre outros fatores, ao elevado custo para obtenção da muda.

Para que a aplicação da micropropagação na produção de mudas torne-se viável comercialmente e possa competir com os métodos tradicionais de propagação (estaquia, enxertia, mergulhia, etc.), é necessário reduzir os custos de produção (ALTMAN, 1999), que se devem em grande parte às perdas causadas pela contaminação in vitro; por desordens fisiológicas e morfológicas nas plantas; à baixa percentagem de sobrevivência das plantas no estádio de aclimatização às condições ex vitro; à necessidade de mão-de-obra especializada, para a intensiva manipulação dos frascos e das plantas (KURATA \& KOZAI, 1992; KOZAI \& KUBOTA, 2001) e; principalmente, ao elevado custo de funcionamento e manutenção das salas de crescimento com regime de luz artificial e temperatura controlada, onde as culturas in vitro são normalmente incubadas (STANDAERT DE METSENAERE, 1991; KODYM \& ZAPATAARIAS, 1999). O desenvolvimento de sistemas de micropropagação fotoautotrófica (produção de micropropágulos sem adição de sacarose no meio de cultura e sob condições ambiente que favoreçam a fotossíntese) (KUBOTA \& TADOKORO, 1999) com o uso de luz natural, surgem como possibilidades potenciais de aumentar a eficiência da micropropagação e auxiliar na redução dos custos, viabilizando-a comercialmente.

Algumas vantagens da micropropagação fotoautotrófica associada à luz natural, em relação ao método convencional de micropropagação, incluem aumento do crescimento das plantas, redução do risco de contaminação microbiana, em virtude da remoção da sacarose do meio de cultura, melhoria das características fisiológicas da planta, devido às condições ambientais de cultivo serem mais naturais, redução do estresse da planta durante a aclimatização, aumentando a percentagem de sobrevivência das mudas (HEMPEL, 1994; ZOBAYED et al., 2000, 2001; AFREEN et al., 2002; KOZAI et al., 2003), eliminação dos custos com iluminação e redução dos custos com reparos e manutenção, e ainda, possibilidade de utilização de instalações simplificadas reduzindo os custos das construções (KODYM \& ZAPATA-ARIAS, 1999).

O objetivo desta revisão é discutir aspectos relacionados à micropropagação fotoautotrófica e utilização da luz natural, como possibilidades para auxiliar a tornar a micropopagação um método de produção de mudas comercialmente viável, através da redução do custo com energia elétrica, e maximização da sobrevivência e qualidade das plantas no final da aclimatização.

\section{Aspectos da micropropagação}

$\mathrm{Na}$ micropropagação convencional, a natureza heterotrófica ou fotomixotrófica de crescimento das plantas é, diretamente ou indiretamente, responsável pela maioria dos fatores relacionados ao custo de produção das plantas micropropagadas (KOZAI \& KUBOTA, 2001). Nela os explantes são cultivados em frascos sem que ocorra troca gasosa, com alta umidade relativa do ar (aproximadamente 98\%), alta concentração de etileno, baixa concentração de $\mathrm{CO}_{2}$ (que decresce de 3.000 a $9.000 \mu \mathrm{mol} \mathrm{mol}^{-1}$ no período escuro para menos de $100 \mu \mathrm{mol} \mathrm{mol}{ }^{-1}$ durante o fotoperíodo), baixa densidade de fluxo de fótons fotossinteticamente ativos, isto é, baixa luminosidade $\left(40-50 \mu \mathrm{mol} \mathrm{m}^{-2} \mathrm{~s}^{-1}\right)$, e com sacarose como maior fonte de energia metabólica (ARIGITA et al., 2002), pelo fato de os explantes apresentarem baixa taxa fotossintética (KOZAI \& KUBOTA, 2001).

Explantes cultivados sob regime heterotrófico originam plantas com elevado conteúdo de água, com grande risco de desidratação e morte durante a aclimatização (KUBOTA \& KOZAI, 1992), ou com desordens anatômicas e fisiológicas que não possibilitam que o aparato fotossintético opere normalmente (ARIGITA et al., 2002), resultando na perda de mudas e de mão-de-obra. As mudanças no ambiente normal de crescimento das plantas têm uma forte influência no desenvolvimento de suas partes aéreas. A superfície e a estrutura interna das folhas e dos caules são alteradas, assemelhando-se a plantas aquáticas. A alta umidade do ar provoca mudanças na estrutura da cutícula, nos depósitos de cera, e nas células do mesófilo e dos estômatos das folhas (HEMPEL, 1993), tornando as plantas suscetíveis a grandes perdas de água por transpiração (FACHINELLO et al., 1995). Além disso, pode ocorrer significativa perda de plantas causada pela

Ciência Rural, v.35, n.4, jul-ago, 2005. 
contaminação microbiana (KOZAI \& KUBOTA, 2001), potencializada pela presença da sacarose no meio de cultura.

\section{Micropropagação fotoautotrófica}

Muitos explantes ou plantas in vitro possuem a habilidade de crescer de forma fotoautotrófica (sem sacarose no meio de cultura e sob condições ambiente que promovam a fotossíntese) (KOZAI, 1991). A micropropagação fotoautotrófica de plantas, além de aumentar o crescimento dos explantes in vitro, também minimiza os riscos de contaminação microbiana, reduz os custos de produção, melhora as características fisiológicas da planta e facilita sua aclimatização às condições ex vitro (AFREEN et al., 2002).

Ao estudarem a micropropagação de espécies lenhosas, como Acacia mangium (acácia), Coffea arabusta (cafeeiro), Eucalyptus camaldulensis (eucalipto), Pinus radiata (pinheiro americano), Rubus idaeus (framboeseira), Garcinia mangostana (mangostão), Azadirachta indica (nim), Paulownia fortunei (quiri), entre outras, KOZAI \& KUBOTA (2001) verificaram que o crescimento de explantes da maioria das espécies foi maior sob condições fotoautotróficas do que sob condições fotomixotróficas. Tomateiros micropropagados de forma fotoautotrófica apresentaram maior vigor, raízes mais desenvolvidas, folhas e ramos mais espessos, e tiveram melhor crescimento após a aclimatização, quando comparados às plantas micropropagadas de forma fotomixotrófica (KUBOTA\& TADOKORO, 1999).

Várias práticas têm sido testadas para promover o crescimento fotoautotrófico das plantas in vitro e, conseqüentemente, reduzir os custos de produção. Entre elas, destacam-se a eliminação total ou parcial da sacarose do meio de cultura (KOZAI \& KUBOTA, 2001; ARIGITA et al., 2002); o aumento da concentração de $\mathrm{CO}_{2}$ e a redução da umidade relativa e da concentração de etileno do frasco de cultivo (KANECHI et al., 1998; KOZAI \& KUBOTA, 2001; ARIGITA et al., 2002); a substituição do ágar por materiais de suporte fibrosos ou porosos, que mostram ser benéficos ao enraizamento sob condições de alta concentração de $\mathrm{CO}_{2}$ e alta luminosidade (KOZAI \& KUBOTA, 2001); e o aumento da intensidade luminosa (KANECHI et al., 1998; KODYM \& ZAPATA-ARIAS, 1999; KOZAI \& KUBOTA, 2001; KODYM \& ZAPATAARIAS, 2001; KODYM et al., 2001).

Quando plantas são cultivadas in vitro, em meio de cultura sem açúcar, surge a necessidade de se aumentar a intensidade luminosa e a difusão de $\mathrm{CO}_{2} \mathrm{e}$ da umidade (vapor da água) em volta da planta (KOZAI \& NGUYEN, 2003), para promover a fotossíntese, a transpiração e o acúmulo de matéria seca (AITKENCHRISTIE et al., 1995; KITAYA et al., 1997). O aumento da intensidade luminosa tem-se conseguido substituindo a luz artificial pela luz natural, com a manutenção das plantas em casa-de-vegetação, ou por pelo uso de janelas externas na sala de crescimento (KODYM \& ZAPATA-ARIAS, 1999) ou clarabóias no telhado (KODYM et al., 2001). Na micropropagação de bananeiras, a maior taxa de multiplicação foi obtida em casa-de-vegetação e em sala de crescimento com luz natural e, por último, em sala de crescimento convencional (KODYM \& ZAPATA-ARIAS, 1999; KODYM \& ZAPATA-ARIAS, 2001).

$\mathrm{O}$ aumento da concentração de $\mathrm{CO}_{2}$, e simultaneamente, a redução da umidade relativa e da concentração de etileno ao redor da planta, têm-se conseguido, utilizando tampas de fechamento dos frascos de cultivo mais permeáveis (filtros permeáveis a gases ou chumaços de algodão, por exemplo) (KOZAI \& NGUYEN, 2003; SANTANA et al., 2003), ou então, por meio do enriquecimento da sala de crescimento com $\mathrm{CO}_{2}$ (KOZAI \& NGUYEN, 2003). O acréscimo da concentração de $\mathrm{CO}_{2}$ promove o aumento da fotossíntese, em função de seu efeito direto sobre a enzima Rubisco (Ribulose 1,5 difosfato carboxilase) (BOWES, 1993; ARIGITA et al., 2002); promove a regulação estomática; prepara as plantas para as condições autotróficas (ARIGITA et al., 2002); e possibilita encurtar ou eliminar totalmente a necessidade de aclimatização ex vitro (KOZAI, 1991; ARIGITA et al., 2002). O decréscimo na umidade relativa com a maior troca gasosa no frasco, aumenta significativamente a taxa de transpiração da planta, e conseqüentemente a absorção de água e de nutrientes (AITKEN-CHRISTIE et al., 1995). Ao mesmo tempo, a redução da umidade relativa reduz a incidência de vitrificação nas plantas, favorece a formação de cutícula nas folhas e o funcionamento normal dos estômatos, aumentando a tolerância ao estresse hídrico (ZOBAYED et al., 2001) e facilitando a aclimatização das plantas.

Com o aumento das trocas gasosas no recipiente de cultivo, a concentração de etileno também é reduzida. $\mathrm{O}$ acúmulo de etileno tem um efeito adverso no desenvolvimento das plantas, afetando a diferenciação, o desenvolvimento, a morfologia e o crescimento das plantas, diminuindo a expansão foliar, o comprimento dos brotos (JACKSON et al., 1991), inibindo a regeneração de novos brotos (BIDDINGTON, 1992) e causando necrose apical nas plantas.

Outra prática utilizada é a substituição do agente geleificante (ágar ou Gelrite) por fibras ou 
materiais de suporte aerados ou porosos, como a vermiculita ou as fibras de celulose, que sob condições de menor umidade relativa, alta concentração de $\mathrm{CO}_{2} \mathrm{e}$ alta luminosidade (observadas na micropropagação fotoautotrófica), tem favorecido o crescimento de plantas in vitro, e aumentado principalmente, seu enraizamento, especialmente a formação de raízes secundárias e de um sistema vascular normal (KOZAI \& KUBOTA, 2001), devido ao aumento da oxigenação e da disponibilidade de nutrientes na zona radicular (KOZAI \& NGUYEN, 2003). Isto também tem facilitado o transplante das plantas para o substrato na aclimatização, de maneira que o material de suporte não necessita ser removido devido a ausência de açúcar, reduzindo a contaminação bacteriana e fúngica, os danos causados às raízes e a mão-de-obra (KOZAI \& KUBOTA, 2001).

Uso da luz natural

$\mathrm{Na}$ cultura de tecidos de plantas, as lâmpadas fluorescentes brancas-frias são a principal fonte de luz utilizada na sala de crescimento, sendo citada em 90\% dos trabalhos científicos (KODYM \& ZAPATA-ARIAS, 1999). A iluminação é responsável por, aproximadamente, $65 \%$ do total de energia elétrica utilizada no laboratório de micropropagação, enquanto que, $25 \%$ são gastos com refrigeração, e o restante (10\%) com esterilização, aquecimento, filtragem, entre outras (KOZAI et al., 2003). Do ponto de vista econômico, a otimização de um sistema comercial de micropropagação requer diminuição do gasto com energia elétrica, que é um dos principais componentes do custo de uma planta micropropagada (GRATTAPAGLIA \& MACHADO, 1998). Na Áustria, por exemplo, o custo da iluminação artificial em salas de crescimento é de US $\$ 3,00$ por metro quadrado por semana, sem incluir os reparos e a manutenção, o que poderia ser eliminado com o uso de salas de crescimento iluminadas com luz natural (KODYM \& ZAPATA-ARIAS, 2001).

A utilização de luz natural apresenta várias vantagens, como a eliminação dos gastos com luz artificial, redução dos custos de manutenção, as instalações são simplificadas diminuindo os custos com construção e, durante a aclimatização o estresse causado à planta é menos intenso (KODYM \& ZAPATA-ARIAS, 1999). No entanto, a disponibilidade de luz varia com a intensidade do sol, que depende das condições climáticas, da hora do dia e da época do ano. Em regiões tropicais e subtropicais, os efeitos das mudanças climáticas são pequenos, entretanto em regiões de clima temperado, estes podem ser aumentados. As maiores taxas de multiplicação de bananeiras micropropagadas sob luz natural foram obtidas durante o verão (KODYM \& ZAPATA-ARIAS, 2001). Neste mesmo trabalho, no inverno, com a luminosidade menos favorável, a taxa de micropropagação decresceu. A decisão pela utilização ou não da luz natural depende da espécie a ser micropropagada, da técnica in vitro utilizada (heterotrófica, fotomixotrófica ou fotoautotrófica) e das condições climáticas do local (KODYM \& ZAPATAARIAS, 1999).

\section{CONCLUSÕES}

A micropropagação fotoautotrófica com o uso da luz natural apresenta grande potencial para auxiliar na redução dos custos de produção de mudas micropropagadas, diretamente, por meio da redução do gasto com energia elétrica, e indiretamente, melhorando a qualidade das mudas, reduzindo a perda de plantas durante a aclimatização e reduzindo a contaminação microbiana. No entanto, as pesquisas com o intuito de utilização da luz natural na micropropagação fotoautotrófica são praticamente inexistentes, apesar de haver fortes razões para sua pesquisa e implementação no Brasil, principalmente pela grande disponibilidade de luz natural ao longo do ano, e por necessitar de novas tecnologias para o setor de produção de mudas.

\section{REFERÊNCIAS}

AFREEN, F. et al. Photoautotrophic culture of Coffea arabusta somatic embryos: photosynthetic ability and growth of different stage embryos. Annals of Botany, London, v.90, p.11-19, 2002.

AITKEn-CHristie, J. et al. (eds). Automation and environmental control in plant tissue culture. Dordrecht, Kluwer Academic, 1995. 574p.

ALTMAN, A. Plant biotechnology in the $21^{\text {st }}$ century: the challenges ahead. EJB Electronic Journal of Biotechnology, Valparaiso, v.2, n.2, p.51-55, 1999. Capturado em 15 out. 2003. Online. Disponível na Internet: http://www.ejb.org/content/ vol2/issue $2 /$ full/1/

ARIGITA, L. et al. Influence of $\mathrm{CO}_{2}$ and sucrose on photosynthesis and transpiration of Actinidia deliciosa explants cultured in vitro. Physiologia Plantarum, Copenhagen, v.115, p.166-173, 2002.

BIDDINGTON, N.L. The influence of ethylene in plant tissue culture. Plant Growth Regulation, The Hague, v.11, p.173-187, 1992.

BOWES, G. Facing the innevitable: plants and increasing atmospheric carbon dioxide. Annual Review of Plant

Ciência Rural, v.35, n.4, jul-ago, 2005. 
Physiology and Plant Molecular Biology, Palo Alto, v.44, p.309-332, 1993.

FACHINELlO, J.C. et al. Propagação de plantas frutíferas de clima temperado. 2.ed. Pelotas : UFPel, 1995. 179p.

GRATTAPAGLIA, D.; MACHADO, M.A. Micropropagação. In: TORRES, A.C. et al. Cultura de tecidos e transformação genética de plantas. Brasília : EmbrapaSPI/Embrapa-CNPH, 1998. V.1, p.183-260.

HEMPEL, M. From micropropagation to "microponics". Practical Hydroponics International, November/ December, p.21-23, 1993. Capturado em 15 out. 2003. Online. Disponível na Internet: http://members.ozemail.com.au/ $\sim$ mhempel/publications/mponic $1 . h t m$

HEMPEL, M. From micropropagation to microponics (part II). Practical Hydroponics \& Greenhouses, May/June, p.17-20, 1994. Capturado em 15 out. 2003. Online Disponível na Internet: http://members.ozemail.com.au/ $\sim$ mhempel/publications/mponic 2 .htm

JACKSON, M.B. et al. Ventilation in plant tissue cultures and effects of poor aeration on ethylene and carbon dioxide accumulation, oxygen depletion and explant development. Annals of Botany, London, v.67, p.229. 237, 1991

KANECHI, M. et al. The effects of carbon dioxide enrichment, natural ventilation, and light intensity on growth, photosynthesis, and transpiration of cauliflower plantlets cultured in vitro photoautotrophically and photomixotrophically. Journal of the American Society for Horticultural Science, Mount Vernon, v.123, n.2, p.176-181, 1998.

KITAYA, Y. et al. Visualization and analysis of air currents on plant tissue culture vessels. Environment Control in Biology, Oxford, v.35, n.2, p.139-141, 1997.

KODYM, A. et al. Cost reduction in the micropropagation of banana by using tubular skylights as source for natural lighting. In vitro Cellular and Developmental Biology Plant, New York, v.37, p.237-242, 2001

KODYM, A.; ZAPATA-ARIAS, F.J. Natural light as an alternative light source for the in vitro culture of banana (Musa acuminata cv. 'Grande Naine'). Plant Cell, Tissue and Organ Culture, The Hague, v.55, p.141145, 1999.

KODYM, A.; ZAPATA-ARIAS, F.J. Low-cost alternatives for the micropropagation of banana. Plant Cell, Tissue and Organ Culture, The Hague, v.66, p.67-71, 2001
KOZAI, T. Micropropagation under photoautotrophic conditions. In: DEBERGH, P.C.; ZIMMERMAN, R.H. (eds) Micropropagation-technology and aplication. Dordrecht: Kluwer Academic, 1991. p.447-469.

KOZAI, T. et al. Efficient production of sweetpotato (Ipomoea batatas (L.) Lam.) propagules and transplants using single node leafy cuttings in closed systems with artificial lighting. Capturado em 20 out. 2003. Online. Disponível na Internet: http:// www.mykz.affrc.go.jp/workshop/ws2000/proceedings/pdf/ p106_kozai.pdf

KOZAI, T; KUBOTA, C. Developing a photoautotrophic micropropagation system for woody plants. Journal of Plant Research, Tokyo, v.114, p.525-537, 2001.

KOZAI, T.; NGUYEN, Q.T. Photoautotrophic micropropagation of woody and tropical plants. In: JAIN, S.M.; ISHII, K. Micropropagation of woody trees and fruits. Dordrecht : Kluwer Academic, 2003. p.757-781.

KUBOTA, C.; KOZAI, T. Growth and net photosynthetic rate of Solanum tuberosum in vitro under forced and natural ventilation. HortScience, Alexandria, v.27, p.1312-1314, 1992.

KUBOTA, C.; TADOKORO, N. Control of microbial contamination for large-scale photoautotrophic micropropagation. In vitro Cellular and Developmental Biology Plant, New York, v.35, p.296-298, 1999.

KURATA, K.; KOZAI, T. (eds). Transplant production systems. Dordrecht : Kluwer Academic, 1992. 299p.

SANTANA, J.R.F. et al. Enraizamento de Annona glabra L. em condições autotróficas. In: CONGRESSO BRASILEIRO DE FLORICULTURA E PLANTAS ORNAMENTAIS, 14.; CONGRESSO BRASILEIRO DE CULTURA DE TECIDOS DE PLANTAS, 1., 2003, Lavras. Anais... Lavras, MG : UFLa/FAEPE, 2003. p. 296 .

STANDAERT DE METSENAERE, R.E.A. Economic considerations. In: DEBERGH, P.C.; ZIMMERMAN, R.H (eds). Micropropagation. Dordrecht : Kluwer Academic, 1991. p.131-140.

ZOBAYED, S.M.A. et al. Quality biomass production via photoautotrophic micropropagation. Acta Horticulturae, The Hague, v.530, p.377-386, 2000

ZOBAYED, S.M.A. et al. Physiology of Eucalyptus plantlets grown photoautotrophically in a scaled-up vessel. In vitro Cellular and Developmental Biology Plant, New York, v.37, p.807-813, 2001 . 